\title{
Religar-se à terra para o céu não cair
}

Reconnect to earth so that heaven doesn't fall

\author{
Benjamim Da Costa ARAÚJO* \\ Universidade Federal do Pará (UFPA)
}

Ivânia dos Santos NEVES**

Universidade Federal do Pará (UFPA)

\begin{abstract}
RESUMO: O presente artigo reflete sobre as possíveis constituições de humanidade a partir de conceitos e concepções fundamentais de ser/sujeito/humano apresentados tanto na perspectiva ameríndia proposta por Viveiros de Castro e outras vozes discursivas quanto no pensamento da ontologia ocidental - ancoradas no antropocentrismo. Atento às diversas narrativas dos pajés Yanomami do grupo Parahiteri presentes no livro "O surgimento dos pássaros" procurou-se fazer aqui uma análise do narrar cosmológico de povos originários com um olhar reflexível - e não menos refratário - ao modo inexorável de ser e de estar neste mundo dos napë (homens) estruturado pela razão. A natureza/planeta como espaço de encontro/confronto de ambas as concepções faz emergir de um lado as contradições de uma razão - e seus mecanismos de dominação e controle do mundo natural - que pressupõe o progresso de uma humanidade, e do outro, um levante de vozes e de vidas indígenas e sua ligação com um mundo natural.
\end{abstract}

PALAVRAS-CHAVES: humanidade, ontologia ocidental e perspectiva Ameríndia.

ABSTRACT:This article reflects on the possible constitutions of humanity from fundamental concepts and conceptions of being/subject/human presented bothin the Amerindian perspective proposed by Viveiros de Castro and other discursive voices and in the thinking of Western

\footnotetext{
* Graduado em Letras Português/Inglês e mestrando em Estudos Linguísticos pelo PPGL-UFPA. E-mail: benjamimca@ufpa.br

** Doutorado em Linguística, na área de Análise do Discurso pela Unicamp (2009). Mestrado em Antropologia pela Universidade Federal do Pará (2004). Licenciatura em Letras pela Universidade Federal do Pará (1992). Prêmio Jabuti 2000, na categoria didático. Experiências na área de Linguística, Comunicação e Antropologia. Desenvolve pesquisas com sociedades indígenas Tupi e experimentações didáticas com as novas tecnologias da informação. Atualmente, é professora do Instituto de Letras e Comunicação - ILC da Universida de Federal do Pará e docente permanente do Progra ma de Pós-Gra duação em Letras. E-mail: ivanian@uol.com.br
} 
ontology - anchored in anthropocentrism. Attentive to the various narratives of the Yanomami shamans of the Parahiteri group present in the book "O surgimento dos pássaros", an attempt was made here to analyze the cosmological narration of native peoples with a reflective - and no less refractory - look at the inexorable way of being and being in this world of napë (men) structured by reason. Nature / planet as a meeting place / confrontation of both conceptions raises on the one hand the contradictions of a reason - and its mechanisms of domination and control of the natural world - which presupposes the progress of a humanity, and on the other, an upheaval voices and indigenous lives and their connection to a natural world.

KEYWORD: humanity, western ontology and Amerindian perspective

\section{INTRODUÇÃO-tanomai thëp $\ddot{e}^{1}$}

“[...] tudo na natureza é transformação, tudo na natureza está em fluxo.

Nós viemos das estrelas, crescemos com os animais e um dia a gente vaivoltar pra poder gerar uma árvore nova, e dessa árvore nova vaipoder ter um pouco da gente também."

[Marcelo Gleiser]

\footnotetext{
"A minha provocação sobre a diaro fim do mundo

é exatamente sempre poder contar mais uma história.

Se pudermos fazerisso, estaremos adiando o fim.

[Ailton Krenak]
}

"O surgimento dos pássaros" - da coleção mundo indígena, organizado por Anne Ballester Soares - é um apanhado de narrativas Yanomami de origens, de surgimentos e/ou de transformações que sobrevoam os espaços sem fronteiras tais quais as da própria extensão da floresta amazônica; sim, para além de uma geografia (que não é apenas Brasil), de um idioma/língua (que não é apenas a dos Yanomami) e de um olhar/perceber/viver o mundo (que não é apenas pela razão humana)... sim, para além (e quem sabe aquém) da razão, aquela postulada por Kant, Heidegger e aliados, e que serviu/serve de fundamento e de paradigma hegemônico com sua proposição antropocêntrica para além das socied ades ocidentais.

\footnotetext{
${ }^{1}$ Gente desconhecida e longínqua.
} 
Estas histórias/saberes foram narradas por pajés Yanomami - sempre de maneira compartilhada com a comunidade - do grupo Parahiteri, transcritas, traduzidas e impressas, e nós (napë, como nomeados por eles!) precisamos abrir este livro como um pássaro abre suas asas para fazer surgir diante de si uma natureza, um mundo, um cosmo. Estas narrativas de surgimentos pressupõem transformações - e transformação é uma semente/semântica constante ao longo destas narrativas - que nos exigem ter o espírito livre/liberto para as experiências e as sensações de uma linguagem indígena com sua manifestação de ser/estar no mundo, permitindo-se um diálogo com a natureza e com os sujeitos que tiveram suas vozes invisibilizadas.

Para as sociedades ou povos originários, em suas perspectivas, os mitos ou as narrativas de criação se distanciam das "historietas" e revelam um importante momento do pensamento humano por designar uma história verdad eira de caráter sagrado e de um exemplar significado, servindo de chave para compreensão da história das sociedades antigas (ELIADE, 1972, p 11). De maneira semelhante ao mito judaico-cristão de Adão e Eva (quando uma mulher falava com uma serpente) ${ }^{2}$ que se manteve/atualizou-se como verdadeiro em sociedades de uma ontologia ocidental, as narrativas dos povos ameríndios também resistem e dão sentidos e identidades ao modo de pensar e viver dos povos indígenas. Os Yanomami - e por extensão os ameríndios - mantém esta relação de sagrado com a natureza, eis a beatitude de origem que também significa manter o mundo estável com seu céu suspenso.

Sabe-se que em determinado tempo da história humana houve uma gradativa e degradável separação entre o homem e a natureza - ao passo que os povos indígenas (povos originários) mantiveram esta relação sagrada e sempre profunda com o mundo natural. Esta reflexão pode ser bem compreendida no diálogo ocorrido entre o cientista Marcelo Gleiser e o líder indígena Ailton Krenak (Conversa Selvagem, 2020)³.

No início, por uma relação de medo e reverência, os homens sacralizaram esta natureza através das religiões em suas diferentes culturas, mas a partir do séc. VI a.C. com o desenvolvimento da filosofia grega, tentando entender a natureza em suas manifestações, houve, como consequência, a criação de mecanismos de dominação e controle do mundo natural. Com o advento do Renascimento, os homens preceituaram que a

\footnotetext{
${ }^{2}$ Gênesis cap. 3 versículos 1 a 5 .

${ }^{3}$ Disponível em: https://www.youtube.com/watch?v=xeAI7GDOefg. Acesso em 17 de nov de 2020
} 
natureza seria uma máquina com certas leis e o método científico entra em ação!), havendo assim uma relação de "suposta" superioridade do homem (razão) para com o mundo natural, e assim mecanizou-se a agricultura e as fontes de energia do planeta em nome de um modelo econômico disseminado nos hemisférios ${ }^{4}$ - norte/sul e ocidental/oriental - deste planeta (GLEISER, 2020).

O homem deixou de se ver|ter como natureza em seu caminho para um suposto progresso da humanidade ou como lamenta o cientista: "A gente nem lembra mais que a gente é parte da natureza" (GLEISER, 2020). Sabe-se que esta configuração de humanidade esteve (e aind a está) explorand o e destruind o a natureza para criar uma vida mecânica e artificial, apartando-se de seu sentido natural. Mas esta configuração de humanidade já vem sendo "incomodada" por outras formas de pensar/perspectivar este mundo, a exemplo das narrativas carregadas de saberes ancestrais dos povos originários, que podem ampliar os modos/manifestações de ser desta humanid ade (fazer caber muitos mundos neste mundo). A ideia que se pretende na essência desta perspectiva

\footnotetext{
"é simplesmente alargar o mundo dos possíveis humanos, mostrando que a tradição cultural européia não detém, nem de fato nem de direito, o monopólio do pensamento" (VIVEIRO DE CASTRO, 2007, p. 71)
}

Na contradança desse movimento mecânico de humanidade, Krenak reflete que as memórias - acerca das origens da vida e das transformações que se dão aqui na Terra - mantidas nas narrativas dos povos originários não deixaram esta relação com o mundo natural escapar, e que estão sempre os religando por este contar de histórias/saberes, voltand o ao início e dialogando com a realidade daquele tempo, o tempo do sagrado, o tempo para reviver a experiência primordial, o tempo de seus ancestrais muito antes desta configuração humana que pensamos e acreditamos ser/ter no mundo. E o que Krenak propõe (pelo olhar dos xamãs ${ }^{5}$ ) pode-se vislumbrar em "Ideias para adiar o fim do mundo" (2019, p. 32)

\footnotetext{
${ }^{4}$ Linhas ima ginárias ou coordena das geográficas, conforme o observatório de uma ciência, o que já denota um olhar|narrar da razão humana.

${ }^{5} \mathrm{Nas}$ comunidades indígenas brasileiras ou sociedades ameríndias da família linguística tupi-guarani, o termo é adotada nas disciplinas de antropologia e etnologia brasileira, e designa o indivíduo responsável pela condução do ritualismo má gico ou a autoridade xamanística, e a quem se atribui suposto poder de comunicar-se com as diversa s potência e seres não-humanos de invocar e controlar espíritos, o que confere à sua ação enca ntatória poderes oraculares, vaticinantes e curativos
} 


\begin{abstract}
"Quando, por vezes, me falam em imaginar outro mundo possível, é no sentido de reordenamento das relações e dos espaços, de novos entendimentos sobre como podemos nos relacionar com aquilo que se
\end{abstract} admite ser a natureza, como se a gente não fosse natureza". (grifos meus)

O relacionar-se com a natureza aqui proposto não é apenas extrair dela árvore/minério para transformá-la em alguns objetos de consumo (mercadorias), mas abstrair e se atrair para ela com outra possibilid ade de ser e estar - se possível, confundir-se com ela - como quem mergulha em suas águas e respira a umidade de suas florestas -, interagindo e intercambiando-se com seus seres naturais, pensando/vivenciand o esta natureza para abrir e ampliar os horizontes de vida. Como sair de uma habitual zona de conforto e propor-se a experienciar o outro? É possível que uma mudança através de novos entendimentos sobre aquilo que nos cerca poderia levar-nos a novas atitudes diante de tudo que há na vida. É o fato de se voltar/envolver-se com a natureza no sentido se reconhecer/religar-se com sua própria essência.

\title{
Yaropë / Yai Thëpë 6
}

Em essência as transformações presentes nas narrativas indígenas revelam uma relação de intercâmbio que se dava com todos os seres (intercâmbio de árvores, de animais, de rios, da lua, de tempestades etc.) permanecendo seres vivos (natureza) como expresso na narrativa "A anta que andava nas árvores":

"Os esquilos viviam como Yanomami: moravam em um xapono no alto das árvores e faziam festas como nós... Um dia eles chamaram as cutias, os caititus, as queixadas, as antas, os papagaios e as maitacas.

(...)

De repente, todos eles se transformaram em animais.

(...)

A anta foi quem caiu primeiro e passou a andar no chão, tornando-se um animal terrestre. Em seguida, o cipó das queixadas arrebentou. Os outros

\footnotetext{
${ }^{6}$ Animais de Caça|Seres Invisíveis
} 
Yanomami, que ficaram na parte superior do cipó se transformaram em macacos cuatás. Assim foi. (p. 98/99) (grifos meus)

Entre as narrativas que exploram as transformações/metamorfoses dos ancestrais animais ${ }^{7}$, a da "A anta que andava nas árvores" revela como alguns dos Yanomami despiram-se de sua humanidade inata para daro surgimento aos animais (e aos humanos) em suas formas variadas, o que de certa forma estará presente em outros mitos ameríndios.

Para este mundo - tal qual nós o percebemos em sua forma firmada nos limites do antropocentrismo - haveria/há uma outra percepção do olhar e do narrar contida em "O surgimento dospássaros", que bem poderia transformar esta forma racional e hegemônica de pensar o mundo em que vivemos. Há potencialmente nestas narrativas um levante das vozes indígenas que confronta a estrutura de pensamento e de valor[ação] da humanid ade, esta forjada e solidificada há séculos pela tradicional epistemologia ocidental em nosso DNA. Há neste levante uma proposta de visão/vivência de mundo que encontra suporte teórico no perspectivismo ameríndio do antropólogo Viveiro de Castro, além de outros pensadores (KOPENAWA, ALBERT, KRENAK) e sobre o mundo indígena. E o que se encontra no pensamento ameríndio, em termos de ontologia, é algo bastante diferente, pois a fonte do sentid o não está localizada na essência do homem - como diria Heidegger -, mas no intercâmbio instável, tenso e contínuo entre humanos e não-humanos, relacionando-se intersubjetivamente com tudo que há na natureza, estabelecendo com esta uma convivência harmônica.

Na construção conceitual do mundo, Hegel - em sua Fenomenologia do espírito - "liberta" o homem "da angústia que o ligava à natureza dada e à sua própria natureza inata de animal" (HEGEL apud VALENTIM, 2018, p. 75) e fund a uma dialética do poder humano sobre todas as coisas, inclusive o próprio homem (senhor e escravo). Assim este projeto de humanidade se forma sob o triste/d rástico signo da dominação e todos os seus mais hostis desdobramentos possíveis; a socialidade entre humanos não seria mais justa, e entre humanos e não-humanos nem existiria. Então a humanidade seria demasiada branca/europeia, demasiada cheia de suas razões, "humana, demasiada humana".

\footnotetext{
${ }^{7}$ Seres da origem mitológica do mundo e, sobretudo, aqueles ancestrais humanos|animais da primeira criação (yaroripë).
} 
Mas esta exclusão de uma possibilidade não-humana no sentido de humanidade apresenta, por si, uma falta (ou falha!?) na perspectiva da ontologia ocidental antropocêntrica, o que Valetim (2002, p. 158) expressa como outra forma de pensar esta incompletude na forma do mundo/humanidade: a extramund anidade ${ }^{8}$, para designar o que não tem lugar na epistemologia de Heidegger, por não ter sentido e nem compreensão para este mundo. É dessa percepção ou outro sentido de ser que se vê florescer o perspectivismo ameríndio - dando humanidade às pedras, às plantas e aos animais... aos não-humanos.

Trata-se de uma mudança radical na perspectiva de compreendermos uma humanidade - em sua constituição e seu modo de ser e estar no mundo - a partir do pensamento ameríndio. Na concepção destes povos, segundo Viveiro de Castro (2002, p. 347)

“(...) o mundo é habitado por diferentes espécies de sujeitos ou pessoas, humanas e não humanas que o apreendem segundo pontos de vistas distintos" (grifos meus)

Para além de uma visão unívoca/soberana do antropocentrismo, a ideia é fazer coexistir neste mundo outros mundos (im)possíveis. Esta apreensão de mundo/humanidade pelos indígenas põe em questão e relativiza os clássicos conceitos estruturados em nosso pensar filosófico ocidental como a própria distinção entre natureza e cultura nos moldes discutid os por Lévi-Strauss. Este dualismo não serve para pensar/refletir a cosmologia ameríndia como podemos perceber nas narrativas, respectivamente, de "O surgimento dos pássaros" e "A transformação dos quatis":

"Todos os animais, as araras, os tucanos, os urus, os inambus, os mutuns, os jacus, os urumutuns, os mutuns-de-traseiro e os jacamins eram gente." (p. 31)

\footnotetext{
${ }^{8}$ Termo cunhado por Michel Haare forjado porMarco A. Valentim.
} 
"Os animais moravam em xapono"; os quatis, as cutias e as antas, as queixadas, os cuatás, os beija-flores, os passarinhos moravam em grupos como nós" (p. 35)

Em algum tempo anterior e longínquo - muitos dirão mítico - em que todas as espécies de plantas e de animais além de seres como os rios, as montanhas, a lua, as tempestades etc., tidos numa tradição ocidental como não-humanos eram, na verdade ou no pensamento e na vivência indígena, humanos ("eram gente" e "como nós") ou constituíram uma humanidade. Havia uma comunicação plena entre estes seres, que participavam e compartilhavam deste mundo sem competir|dominar ao outro. Essa atribuição de "gente" aos animais, trazida pela memória e revivificada na narrativa Yanomami, revela uma preservação de valores de um povo, que presentifica pensamentos e comportamentos transposicionados por este [re]contar das histórias de uma geração a outra além de religar-se no tempo e no espaço às expressões da natureza.

Por não haver esta distinção entre natureza e cultura, como refletido a partir do expresso nas narrativas Yanomami, era mais do que normal que o jacaré ensinasse os napë [homens] a fazer fogo, que alguns Yanomami se transformassem em peixe, que o tatu fabricasse o machado, que o escorpião flechasse a lua ou que uma criança se transforma em pássaro, e isto reforça em sua essência que humanos e não-humanos não eram distinguidos com tanta nitidez e que estes seres atuavam com alguns artifícios de civilização - eis aqui uma perspectiva ameríndia de humanidade.

Mesmo atualmente, seja nestas narrativas ou na vivência do dia-a-dia, os Yanomami - e por extensão os ameríndios - não percebem e nem sentem a cultura, tal qual nós assim a denominamos, como um atributo dos humanos, pois estes ditos nãohumanos (as plantas, os animais e os fenômenos da natureza) também são tidos por eles (ameríndios) como possuidores de uma força e vivem conforme suas próprias normas.

Perseguind o o perspectivismo de Viveiros de Castro, a concepção indígena (ou o seu pensamento) é profundamente diferente dos humanos no modo de olhar para os nãohumanos (e aqui está também a natureza), pois indígenas não veem o outro como objeto - "os animais são gente, ou se veem como pessoas" (CASTRO, p. 351) - e tudo isto se

\footnotetext{
${ }^{9} \mathrm{~A}$ casa, a a ldeia - os grupos yanomami são geralmente construídos por uma casa plurifamiliar em forma de cone ou de cone truncado chamado yano ou xapono, ou por aldeias compostas de casas de tipo retangulares.
} 
dá porque a noção ou ideia de humanidade é, de fato, uma questão de perspectiva, e em que os xamãs (ou pajés) têm acesso a essa humanidade dos ditos não-humanos, uma vez que estes se apresentam com "diferentes roupagens". O que se forma ou podemos refletir aqui são as noções do ser e os seus desdobramentos, pois há diversas perspectivas destes seres, na forma como os animais se veem e veem o homem e|ou ainda os espíritos; como os homens se veem e veem os animais e ou ainda os espíritos e como os espíritos se veem e veem os animais e ou ainda os homens. Essa pluralidade na perspectiva ameríndia abre para outros possíveis de participação de uma humanidade - não haveria uma unicidade de sujeito - com atuação de diferentes seres/entes [humanos e não-humanos].

É importante ressaltar que diante destas narrativas orais há uma potência de valores históricos preservados ou mantidos sob uma língua/idioma/dialeto que estes povos carregam e podem nos revelar - e já o fazem há algum tempo! - uma constituição dehumanidade outra (que não a fundad a na ontologia ocidental), e que por sua tradicional forma de lhe dar com a natureza estabelecem|sustentam uma ligação sagrada com esta, convivendo em equilíbrio e em harmonia com todos os seus pares e parentes - e aqui estão as plantas, os animais, os rios, as montanhas etc - e havendo um reconhecimento do outro pela forma como os indígenas se envolveram/envolvem com a subjetivação desta natureza. Percebemos esta situação na narrativa "A queda do céu", revelando o surgimento dos Yanomami ${ }^{10}$ na terra e sua multiplicação nas florestas:

"Apesar de estarmos nas alturas, nós existimos. Assim, se essas montanhas não houvessem existido e se não se erguessem, nossos antepassados não haveriam saído, não haveriam existido.

Eles ficaram espertos por causa destas cavernas.

Quando começou a estrondar lá em cima, quando o evento se aproximava, ele avisou seu povo. Os outros não sabiam:

- Vamos, meus jovens, nós da região central vamos escapar por estas montanhas, pois eu não sou tolo! Vocês não serão esmagados. Nós apenas

\footnotetext{
${ }^{10}$ Há nesta narrativa [Aqueda do céu] o registro da origem do grupo Parahiterie que se encaixa no meio da história dos Yanomami. Segundo os Parahiteri alguns grupos foram se extinguindo e de "gerações posteriores foi que apareceram os nossos antepassados" [pág. 56]. Há outras concepções para este surgimento em que Os Yanomami remetem sua origem à copulação do demiurgo Omama - ou Omawë com a filha do monstro aquático Tëpërësiki - ou Raharariwë -, dono das plantas cultivadas. A Omama é a tribuída a origem das regras da socieda de e da cultura ya nomami atual, bem como a criação dos espíritos auxiliares dos pajés: os "xapiripë ".
} 
sobreviveremos nesta região e, se for preciso, passaremos para o outro lado do céu. Limpem essa montanha! - disse - Abram o caminho! (p. 54) (grifos meus)

A sobrevivência destes povos está relacionada à vida no planeta em suas múltiplas dimensões presentes no ambiente natural (se essas montanhas não houvessem existido...), e não condicionados às relações de dominação e exploração dos recursos naturais - aliás, a natureza não é tida como "recurso", e nem a terra é vista como "propriedade privada" no sentido econômico e desenvolvimentista destas palavras. A natureza se apresenta como mãe-provedora das necessidades de uma humanidade, mas isto não quer significar que estes humanos tenham de agir como aproveitadores desta situação, mas sim agir como os povos originários - os guardiões destas florestas - que não se denominam donos da terra, mas são a terra, nutrindo-a e sendo nutridos por ela, pois se a natureza não for protegid a faltará ar|ambiência para todos viverem.

Assim os povos indígenas protagonizam uma convivência/conservação nesta natureza limpem essa montanha! -, como reconhecimento de valor(ação), pois estas montanhas lugares sagrados e moradas de espíritos - providenciaram a sobrevivência destes povos para acesso ao outro lado do céu. A montanha é tida como uma entidade viva e que se insere numa complexa d inâmica cosmológica em que humanos e não-humanos têm suas relações subjetivas.

Há uma consciência neste narrador que o faz ligar-se ao ambiente que ali se instalou, pois percebe um estado de alerta por um céu que estava por cair - Quando começou a estrondar lá em cima -, e em suas memórias já (re)conhecia este evento por vir, esta ação catastrófica na natureza. Compreendia como ninguém estes sinais, e diante deles tomaria as atitudes certas, abriria um caminho possível para sobreviver a esta inevitável queda.

De título homônimo a uma das narrativas dos pajés parahiteri, "A queda do céu" (2015), de Davi Kopenawa e Bruce Albert, traz uma monumental crítica ao modelo de sociedade que aí está, mas também uma "mensagem" semelhante a daqueles pajés, mas com tons mais dramáticos e sim, se em outros tempos o céu já caiu, não é menos verdade|provável que a qualquer instante este céu poderá cair. Para Kopenawa o susto|assombro de uma realidade estaria mais evidente em seus sonhos: 
Naquela cidade, na verdade não foi a altura dos prédios o que mais me assustou. Foram outras coisas, que se revelaram durante os meus sonhos. Assim, certa noite, vi também o céu ser incendiado pelo calor da fumaça das fábricas. Os trovões, os seres raios e os fantasmas dos antigos mortos estavam cercados de chamas imensas. Depois, o céu começou a desmoronar sobre a terra com grande estrondo. Isso sim era mesmo assustador! Onde os brancos vivem, o céu é baixo e eles não param de cozer grandes quantidades de minério e de petróleo. Por isso as fumaças de suas fábricas sobem sem trégua para o peito do céu. Isso o torna muito seco, quebradiço e inflamável como gasolina. Ressecado pelo calor, torna-se frágil e se desfaz em pedaços, como uma roupa velha. Tudo isso preocupa muito os xapiri. (p. 434) (grifos meus)

Atualizando a mensagem Yanomami com seus sonhos|signos|sinais escatológicos - vi também o céu ser incendiado pelo calor da fumaça das fábricas -, Kopenawa antecipa um possível desastre socioambiental de nossa era (antropocêntrica), em consequência de diversas práticas danosas/daninhas implantadas nos últimos séculos pelos napë em sua relação com a natureza - entre elas: genocidas, etnocidas e ecocidas, assim (des)caminha uma humanidade que marcha para um abismo com insensatez/insanidade.

Os povos originários têm nas suas narrativas a presença de uma "raiz do saber" que está muito anterior ao fazer da colonização dos ameríndios pelos europeus - em seus estados de exploração da natureza e do ser feita por alguns humanos; a presença de um tesouro de linguagem que não deveria ser ignorado e a presença de um pensamento que os liga ao que há de mais originário na natureza deste mundo e/ou no mundo desta natureza. Menos preocupado com o desenvolvimento (no sentido de progresso econômico), estes povos ocupam-se com o envolvimento de seu ser com a natureza, podendo-se fazer uma atribuição de intersubjetividade (e por que não dizer "humanidade") aos seres da natureza através de um processo de interação entre humanos e não-humano.

$\mathrm{Na}$ narrativa "O surgimento da banana" (p. 92/93) esse reconhecimento de intersubjetividade é evidenciado quando o rio - perseguindo/assediando uma mulher bonita por quem sente-se atraído - avança sobre as roças e entra nas casas: 
O rio desejava a mulher menstruada porque ela era bonita.

$[\ldots]$

$\mathrm{O}$ rio disse:

- Meu sogro, quero uma mulher! Me dê a sua filha!

$\mathrm{O}$ rio entrou, perseguindo a mulher. $\mathrm{O}$ rio entrou rápido. Olha só a água.

Ela entrava por trás das casas, apesar de a terra ser alta.

$[\ldots]$

- Eu, apesar de ser água, farei dela a mãe d'água! (grifos meus)

Percebe-se nestas passagens as possíveis relações de subjetividade, em que um humano (o pai da mulher menstruada) reconhece a posição de sujeito de um não-humano (rio/águas), a partir de sua interação com o outro, ou seja, o rio também é gente/pessoa, uma vez que se atribuíram ao rio "as capacidades de intencionalidade consciente e de 'agência' que definem a posição de sujeito" [CASTRO, 2000, p. 126].

Por esta perspectiva modifica-se a noção|constituição de ser, pois o outro em seu atributo de sujeito na relação|interação revela sua alteridade. Diferente da ontologia ocidental de uma relação dialética e social humana e a sua imperatividade do ser/poder, o perspectivismo ameríndio propõe a interatividade do sujeito em relação aos outros (respeito/reconhecimento de alteridade) como a possibilid ade de alteração d a essência do ser|sujeito pela interação com o outro.

E quais as implicações desta alteridade na constituição do sujeito? Ora, em se alterando o ser altera-se em outra escala o próprio mundo, altera-se em sentido mais amplo a ontologia de humanidade. O que pode ser visualizado neste episódio do "casamento" entre uma índia/humano e um rio/não-humano? Em relação à intersubjetividade já posta, contempla-se uma ligação destes seres com seus desdobramentos neste espaço social/xapono, pois agora a partir da nova relação com o rio, o pai torna-se "sogro" e a filha "esposa" além de se transformar em "mãe d'água" e "boto". Há uma integração a partir do envolvimento destes seres e que faz fluir o próprio cosmo local e o que disto pode-se desdobrar em global.

\section{Considerações - Yama ki hwërimamouwi thëã oni ${ }^{11}$}

\footnotetext{
${ }^{11}$ Palavras escritas para nos curar
} 
O aprendizado do povo indígena volta-se para a convivência|conservação desta natureza (rio) numa relação intersubjetiva, ampliando o conceito de coletividade/socied ade/humanidade - contrário ao pensamento de um modelo econômico de exploração|extração da natureza, visto tanto num passado colonial destes país|continente, quanto nos projetos desenvolvimentistas atuais como o agronegócio com essa agenda de "progresso" (com os desmatamentos, as construções de barragens, as minerações etc.), dando uma tônica de humanidade como uma gigantesca máquina de produção de entropia que caminha no sentido de acelerar a desintegração da natureza, e em particular, de lugares considerados sagrados por estes indígenas.

Nessa humanidade muitos dos episódios que estes humanos protagonizaram foi no sentido de tocarem/pisarem o chão deste planeta a ponto de parece ter feito estremecer um pedaço do céu, e ainda que isto soe como uma metáfora ou ressoe como um sonho para Kopenawa, tem o susto de uma realidade (Ressecado pelo calor, torna-se frágil e se desfaz em pedaços, como uma roupa velha); num mundo longínquo ou mesmo próximo a "civilização dos brancos/europeus" com seu modo de ver/viver sempre que se aproximou/apropriou do solo deste continente "americano" deixou muitas vezes um rastro mortífero no ar e que a cad a passo ecoou violentamente em direção de alguma terra à vista.

Há ainda um ambiente turvo circundando os povos ameríndios, saqueando os lugares sagrados, poluindo rios, esvaziando florestas etc., e de maneira ainda mais danosa, sob estes impactos, uma desnaturalização destes povos. Certamente que há uma necessidade de se reconhecer que os impactos da invasão/colonização europeia neste "continente amazônico" foram mais destrutivos do que pensamos/admitimos tradicionalmente (VIVEIRO de CASTRO, p. 340).

Os povos indígenas e seus saberes confrontam com esta violência/violação que ecoam até hoje, e resistem à intensa tentativa de aind a silenciar esta cultura, estas vozes, estas narrativas que se fazem presentes e atuantes com algum encanto nesta mesma Amazônia onde os pássaros ressurgem com suas asas para um voo livre/longínquo e quiçá façam inspirar o pensamento de outros humanos e não-humanos para que - uma vez atravessado por outra perspectiva - possam continuar um canto/conto para sustentar o céu. 


\section{REFERÊNCIAS}

BÍBLIA, Português. A Bíblia Sagrada: Antigo e Novo Testamento. Tradução de João Ferreira de Almeida. Edição rev. e atualizada no Brasil. Sociedade Bíblica do Brasil. Brasília, 1986.

Conversa Selvagem - Ailton Krenak e Marcelo Gleiser. Disponível em: www.youtube.com/watch?v=xeAI7GDOefg. Acesso em 17 de novembro de 2020.

ELIADE, Mircea. Mito e realidade. Ed. Perspectiva, São Paulo, 1972. 179 pp.

KOPENAWA, Davi e ALBERT, Bruce. A queda do céu Palavras de um xamã yanomami. São Paulo: Companhia das Letras, 2015.

KRENAK, Ailton. Ideias para adiar o fim do mundo. Companhia das Letras. 2019.

PAJES PARAHITERI. O surgimento dos pássaros / Naroriwe. Org. por Anne Ballester Soares. Rio de Janeiro: Ed. Hedra, 2018. 129 p.

SZTUTMAN, Renato [Org.]. Eduardo Viveiros de Castro. [Encontros]. Rio de Janeiro: Azougue, 2007. 261 p.

VALENTIM, Marco Antonio. Extramundanidade e sobrenatureza: ensaios de ontologia infund amental. Cultura e Barbárie. Desterro [Florianópolis], 2018.

VIVEIRO DE CASTRO, Eduardo B. A Inconstância da Alma Selvagem e outros Ensaios de Antropologia. São Paulo: Cosac \& Naify. 2002. 552 pp. 